\title{
"Eu vi o mundo... ele começava no Recife"
}

Maria de Lourdes Eleutério

O título deste texto é aquele do famoso painel em que o pintor pernambucano Cícero Dias retratou a vida do Nordeste brasileiro, notadamente Recife. Lá estão as danças, os folguedos, cenas da mais genuína cultura popular, nus femininos. Realizado quando Cícero ainda era muito jovem, a obra parece, em seu sintomático nome, prenunciar a vida cosmopolita que ele teria e, concomitantemente, suas constantes referências à sua terra natal.

A observação desta obra faz-nos lembrar o acervo iconográfico que podemos apreciar na Biblioteca Oliveira Lima localizada na Universidade Católica da América, em Washington. Entre telas de pintura histórica (que também remetem à história do nordeste), retratos de Oliveira Lima e da família imperial brasileira, destacamos aqui as paisagens e vistas recifences. ${ }^{2}$ Deve-se ressaltar que a presença do Recife talvez seja a referência maior do acervo da Biblioteca, entretanto vamos circunscrever nossa apreciação, nesse momento, às telas cujo tema seja a cidade do Recife.

A primeira delas é de Frans Post, portanto do século XVII, e as demais são do início do XX, elaboradas por pintores locais como Álvaro Amorim, Balthasar da Câmara e Jerônimo Telles Jr., e ainda, o carioca Antonio Parreiras, quando de sua passagem pela cidade. Tais imagens acompanharam Oliveira Lima pelos lugares nos quais morou. $\mathrm{O}$ que representam para o diplomata é o que buscamos analisar, integrando à nossa reflexão as cartas que lhe foram enviadas por esses pintores, o que nos possibilitou entender em que circunstâncias as obras vieram a compor o referido conjunto. Acrescente-se às obras de arte e às cartas, os inúmeros artigos de jornal colecionados e arquivados cronologicamente em scrapbooks, por Flora de Oliveira Lima, ampliando assim a inteligibilidade acerca das relações entre os produtores de arte e o colecionador na constituição do acervo.

Observemos, inicialmente, a presença do pintor, gravador e desenhista Frans Post (1612-1680) na coleção. Segundo Evaldo Cabral de Mello, citando o estudioso Souza Leão, ${ }^{3}$ nada teria restado das pinturas realizadas no Brasil holandês após a Restauração. As primeiras obras do artista foram trazidas ao nosso país nos finais do século XIX, adquiridas por Eduardo Prado, ou pelos historiadores pernambucanos Alfredo de Carvalho e Oliveira Lima. Acrescente-se à informação aposta em Rubro veio, a referência, em um artigo mais antigo, de 1932, feita por um contemporâneo de Oliveira Lima, Eustórgio Wanderley. Este, cita o livro de Pedro Souto Maior, Fatos pernambucanos, que amplia a lista dos possuidores de Post. No Recife haveria ainda, o dr. Silvio Cravo e o comendador Ferreira Baltar (amigo e missivista de Oliveira Lima), como colecionadores do holandês. Baltar teria em sua residência "um verdadeiro museu de arte e raridades (...) curiosa e valiosíssima coleção de gravuras dos irmãos Post.” Wanderley é enfático ao argumentar: "Não nos acoimem de bairristas quando queremos reivindicar para nossa terra os primórdios da arte, da pintura brasileira, quando nos orgulhamos em dizer que foi aqui, onde primei- 
ro se transladou para a tela a paisagem belíssima da terra dos mangueirais em flor - a heróica Itamaracá, - e onde também, pela primeira vez, refulgiu num quadro, o azul e formoso céu de Rio Formoso."

Sabedor de que no imaginário pernambucano a paisagem inaugural pertence a Frans Post, Manuel Oliveira Lima teria tratado de adquirir uma tela do holandês considerado como o fundador da concepção de paisagem americana. Antes da vinda de Nassau, a América existia como terra e natureza tropical, mas não como "paisagem", já que esta não havia sido pintada como "representação" 5 . O quadro adquirido pelo historiador é de 1647. ${ }^{6}$ É possível que Post tenha chegado, como os demais artistas, em 1637, permanecendo no Brasil até 1644, sendo assim a tela de Oliveira Lima integra a chamada $2^{a}$ fase do pintor, já de volta à sua terra natal, quando então reproduz as imagens dos cadernos que trouxera do Nordeste brasileiro.

Ao período de permanência no Brasil pertencem pinturas mais claras, vivas. Já ao segundo período confluem telas mais sombrias, com luminosidade atenuada, mais européia. O trabalho em questão parece-nos algo intermediário, apresentando um céu azulclaro carregado de nuvens brancas. Duas características postianas estão evidentes na obra de adquirida por Oliveira Lima. A árvore, no primeiro plano, nesse caso nas duas laterais do quadro, denota a intenção de enfatizar a profundidade abarcada pelo pincel que descreve a natureza. Os vultos, humanos ou de animais, miniaturizados, também são uma constante nas duas fases iniciais da produção do pintor. ${ }^{7}$

Geralmente a produção de Post é caracterizada pelo enaltecimento da visão edênica do país recentemente conhecido: fauna, flora, frondosas árvores de verdes intensos, céus de azuis luminosos, vastidão de terras, síntese primeira de uma perspectiva sempre a se perder de vista. Olhar a tela em questão é vislumbrar o distante: terras para o interior ou mares para o exterior, isto é, o pêndulo constante na vida do diplomata.

Outra característica postiana pode ter contado para a escolha de Oliveira Lima: a de que Post representou a paisagem brasileira como um holandês. Ele teria realizado "fantasias paisagísticas," reinventando, de memória, o que vira em Pernambuco. ${ }^{8}$ Não seria este aliás um exercício constante na vida e na obra do próprio Oliveira Lima, ele mesmo um historiador, crítico literário e de artes plásticas que, sendo diplomata, vivera mais tempo no exterior do que na terra em que nascera, alvo de seus estudos históricos?

Ainda na chave da compreensão da paisagem e demais pinturas produzidas pelos Países Baixos, o historiador Teixeira Leite ${ }^{9}$ aponta a necessidade de confrontar a produção de Post com a de outros artistas nassovianos, e o importante papel que lhe devemos atribuir, com o que era realizado anteriormente. Segundo ele, cartógrafos, desenhistas e pintores europeus produziam quase sempre "de ouvido", assim contemplando grande diversidade de monstros e variado exotismo.

O entresséculos, XV para o XVI, além de ampliar consideravelmente os horizontes geográficos, passa a ter a natureza como objeto de reflexão. Mas, segundo estudiosos, a relevância da discussão seria mais etnográfica que sobre paisagem. Post comparece ainda na biblioteca do diplomata como ilustrador do "Rerum per octennium in brasiliae", a raríssima obra editada em 1647 por Caspar van Baerle. Quando o artista voltou para a Holanda, além de continuar pintando a paisagem brasileira, permaneceu a serviço de 
Nassau, que franqueou seus arquivos para que se registrasse a administração empreendida por ele no Brasil. ${ }^{10}$

Na coleção de quadros de Oliveira Lima, diversificada em termos de autores e gêneros, encontramos o pintor, restaurador, cenógrafo, escultor e professor, Álvaro de Oliveira Amorim. O artista teria nascido no Pará, em data incerta, segundo os dicionários pesquisados. Entre seus alunos destaca-se o escultor Francisco Brennand, que nos relata ter sido Amorim contratado como restaurador por seu pai que acabara de comprar uma coleção de arte. Brennand começa a convidar, desde então, diversos artistas para pintar a paisagem natural do engenho São João, de sua propriedade, e entre eles estava o próprio Álvaro Amorim. "Amorim me aproximou da pintura, dando-me de presente um cavalete, ensinando-me a misturar tintas, a usar os pincéis e me apresentando a outros professores da Escola de Belas Artes."11

O tema preferido de Amorim seria, segundo Lucílo Varejão, o de fixar ruínas e nesse gênero, "há coisas suas do Forte do Buraco, Cruz do Patrão, Megaipe, capazes de emparelhar com as boas criações dos mestres da especialidade." 12 Esta informação é muito pertinente se a relacionarmos com as duas telas encontradas na Biblioteca Oliveira Lima. Uma delas, A cruz do patrão, datada de 1916, foi comprada conforme carta redigida pelo pintor ao diplomata, em 1918: "Venho por meio d'esta pedir a V. Ex. o grande favor de adquirir a tela "Cruz do patrão" que acompanha esta carta."

Como se sabe, a Cruz do patrão é um marco dos tempos da escravidão ainda hoje existente no Recife. A outra obra, também de 1916, intitula-se Ruinas do forte holandês do Buraco. O referido forte é considerado uma das mais preciosas relíquias do período holandês. Sua construção foi iniciada pelos portugueses e concluída pelos holandeses em 1631. Após a Restauração pernambucana, foi reconstruído pelos luso-brasileiros. Erguido no istmo que liga Olinda a Recife, está entre o mar e o Rio Beberibe, local conhecido como Buraco porque ficava em frente ao Buraco de Santiago, hoje Tacaruna. ${ }^{13}$ A coleção conta com outra representação do local, que é o esboço de Antonio Parreiras realizado em 1917, tela feita em Recife quando da visita de Parreiras àquela cidade.

As informações sobre Amorim são parcas, mas sabe-se que o pintor atuou na década de 40, só ou em companhia de outros artistas, executando cenários de peças beneficentes levadas pelo afamado grupo Teatro dos Amadores de Recife, bem como pelo Teatro infantil de Pernambuco, ambos representando sempre no teatro Santa Isabel. O nome do pintor está registrado, por exemplo, como realizador dos cenários das peças $D r$ Knock, A exilada, Alto mar, entre outras.

Álvaro criou em 1931 junto de artistas como Bibiano Silva, Balthasar da Câmara, Fédora Monteiro, todos presentes na coleção Oliveira Lima, a Escola de Belas Artes de Pernambuco, instituição que, surgida em meio a extremas dificuldades financeiras, viveu de doações e da tenacidade seus idealizadores. A Escola manteve os propósitos daquele que foi o primeiro empreendimento preocupado com artes em Pernambuco, o chamado Círculo de Belas Artes, do qual Oliveira Lima era membro. No ano seguinte, Amorim montou ateliê justamente com Balthasar da Câmara e Telles Jr.

Como dissemos, o acervo Oliveira Lima, possui um Balthasar da Câmara. A tela foi um presente, como podemos verificar pela própria dedicatória aposta a ela: "Ao Dr. OL esta pequena lembrança oferece o Patrício que o admira de coração.” Trata-se de uma manifestação 
de agradecimento à recomendação dada pelo historiador ao governador da Paraíba, local onde o pintor exporia suas telas. Pela carta ficamos sabendo que Balthasar esteve em Parnamirim, então residência de Oliveira Lima, solicitando tal recomendação. Observase a ênfase que marca seu gesto, em mais um fragmento da pequena missiva: "Esta pequena oferta não significa somente uma lembrança do patrício conterrâneo, não. É um pedaço de minha alma, é um pouco do meu Eu que se sente feliz na convivência inseparável do brasileiro querido: Dr Oliveira Lima; muito embora tão distante das terras brasílicas." 14

O pintor nos esclarece sobre o que retratou: "A xilo-pintura que vos ofereço é um fragmento do grande forte dos holandeses, situado em Cabedelo. É pena que esta parte do forte, tão característica dos fortes holandeses, esteja tão danificada, como se pode reconhecer pelo forte do Buraco."

O forte de Cabedelo é uma imagem fundamental para o sentimento de pertencimento ao lugar e à condição de colônia de Portugal, portanto, da interação luso-brasileira sempre presente na vida do diplomata que, sendo brasileiro, teve parte substancial de sua existência vivida em Portugal. Sabe-se que Câmara também esculpiu o busto de Oliveira Lima, mas este não se encontra no acervo da Biblioteca. O artista foi discípulo de Carlos Chambelland, que esteve por alguns anos em Recife, a partir de 1913, depois de sua estada na Europa. A coleção de Oliveira Lima possui duas telas desse artista que se deixou impressionar pela Recife daqueles tempos. ${ }^{15}$

Balthasar José Estevão Dorneles da Câmara, após estudar na Escola Nacional de Belas Artes, foi professor de pintura de modelo vivo da Escola de Belas Artes do Recife. Segundo os dicionários consultados, o pintor deu preferência pelos temas regionais, embora tenha realizado uma série de retratos de brasileiros ilustres e personalidades expressivas do meio intelectual recifense, como por exemplo, o da editora norte-americana Blanche Knopf para o Instituto Joaquim Nabuco, para o qual, aliás, realizou mais de 70 obras encontradas atualmente em sua Pinacoteca.

A presença de Amorim e Câmara na coleção Oliveira Lima permite-nos inferir que, sem prestígio, e até hoje muito pouco conhecidos, ambos buscavam, através de suas cartas, apresentar-se ao homem influente, também jornalista, talvez única condição de tornarem-se conhecidos, pois vivendo numa época em que os auxílios governamentais escasseavam, ainda mais fora do Rio de Janeiro e do emergente estado de São Paulo, tais artistas se viam na contingência de usar de expedientes como os dispostos nas missivas, na tentativa de obter alguma projeção.

Naquela época exercer o magistério era a possibilidade mais viável para ganhar a vida. Os artistas ministravam aulas de desenho ou pintura, tanto nas escolas que a República criava, quanto particularmente para moças da elite. Era hábito constante, mesmo no Rio de Janeiro, e com artistas já reconhecidos, como os irmãos Bernardelli, ${ }^{16}$ tornando-se mais premente em um lugares onde a produção artística tinha limitações extremas. Portanto, Amorim e Câmara dedicavam-se ao ensino, assim como Jerônimo José Telles Jr: (Recife 1851-Recife 1914), o mais importante paisagista pernambucano da virada do século XIX - XX e atualmente o mais reconhecido representante do paisagismo nordestino. Com este, Oliveira Lima teve uma proximidade maior, como podemos aquilatar 
pelas várias telas que dele comprou, bem como de uma troca de correspondência mais volumosa.

O pintor e professor experimentou varias profissões antes de receber lições de pintura de Eduardo de Martino, de desenho de Agostinho José da Mota, no Liceu de Arte e Ofícios do Rio de Janeiro, bem como de Aurélio de Figueiredo (de quem a coleção Oliveira Lima possui duas obras), quando da estada desse artista no Recife. Por sua vez, Telles Jr. ensinou os também pintores pernambucanos Mário Nunes, Walfrido Mauricéia, Emílio Cardoso Ayres, a tia deste, mãe do pintor Lula Cardoso Ayres, e ainda o pintor e dicionarista paraense Teodoro Braga.

Talvez o mais ilustre aluno de Telles Jr. tenha sido Gilberto Freyre, a quem deu aulas de desenho. O sociólogo assim o definiu: "mestre exigente e absorvente, (...) sempre ríspido, rude, autoritário." O pintor, em sua persona de professor por necessidade financeira, não teria a menor paciência para ensinar, sobretudo às crianças. Diz Freyre que, sendo menino de feitio irrequieto e elaboração ousada nas lições prescritas pelo Mestre, era recriminado por este tão severamente, e quase sempre desestimulado de forma categórica em seu "gosto pelo desenho e entusiasmo pelas cores." Tal experiência o teria limitado a esboçar caricaturas "como um vício secreto (...) uma compensação de impotência artística." 17

Ao considerar-se um "discípulo frustrado" de Telles Jr., Freyre observa que o pintor, por sua vez, fora um menino oriundo de uma família de precária condição financeira e tivera um pai extremamente autoritário, justificando, assim, a severidade de seu professor ao recorrer à autobiografia, ${ }^{18}$ na qual o pintor descreve as privações pelas quais passara, o trabalho no comércio desde a mais tenra idade, sua iniciação autodidata, para depois dedicar-se efetivamente à arte, não sem grandes dificuldades. Em 1887 o artista, finalmente montou seu ateliê na rua da Imperatriz no Recife, mas abdicou desse espaço de trabalho logo depois, observando que "o negócio da pintura muito daria se en tivesse um capital", para fazer frente às enormes despesas e ao enorme trabalho a enfrentar. Telles relembra em tom de lamento: "Me encarregava de pintura e decoração de casas, mas o pessoal de ajudantes e operários era a gente mais infame e ordinária que existe, e os desgostos eram tantos que foi o que mais me obrigon a fechar a oficina." 19

Talvez por isso, sempre procurando dinamizar o seu meio, torna-se sócio do recém criado Liceu de Artes e Ofícios, para capacitar mão de obra especializada. Registre-se, como o fez Gilberto Freyre, a relevância da participação de Telles Jr. na sociedade recifense de seu tempo. Freyre nos fala da dedicação do pintor-educador, especialmente ao Liceu. "Antes de professor de escola de engenharia e de colégio elegante de moças, ensinou rapazes pobres e, na maioria, de cor, no Liceu. Em vez de pintor que se contentasse em pintar quadros para comendadores viajados e de médicos colecionadores de obras de arte," Telles Jr - esforçando-se sempre para democratizar o ensino e a fruição da arte preocupava-se com a integração do maior número de pessoas ao usufruto das artes. Para tanto, organizou para a Instituição uma série de exposições entre 1881 e 1888, constituiu a banda do Liceu, promoveu o ensino da marcenaria, da carpintaria, incentivou aulas de escultura, desenho, música e outras atividades. ${ }^{20}$

Telles Jr. também foi o responsável pela biblioteca da referida escola e esmerou-se na escolha dos títulos para compô-la, sobretudo na bibliografia sobre Barbizon. A pequena vila próxima a Fontainebleau, conhecida por seus pintores paisagistas que se reuniam 
para retratar a natureza, a luz e a coloração da atmosfera, in loco, ficou conhecida como sinônimo de um exercício do fazer pictórico contrário ao acadêmico e à paisagem produzida em estúdio. O "pintor da mata pernambucana", como era chamado por seus conterrâneos, parece ter-se imbuído dos ensinamentos de Barbizon, partilhando-os com seus discípulos em leituras e ao entranhar-se nas matas em que prazerosamente executava suas telas.

A Biblioteca Oliveira Lima possui cinco obras do pintor. Elas trazem a peculiaridade de se auto- explicarem, como podemos ler, por exemplo, no verso de Forte do Picão, de 1907. A edificação desse local pelos portugueses ocorreu entre 1612 e 1614 e foi inicialmente chamado de São Francisco da Barral. Trata-se de um dos mais importantes pontos da resistência contra os holandeses. Quando da reconquista, recebeu o nome de Picão, e Telles Jr. nos explica o porquê desse nome: "Forte da Barra de Suape no Cabo de Santo Agostinho também chamado de Forte do Picão devido a uma pedra que tem a entrada da barra e que se descobre nas marés baixas a que chamam picão, como se vê neste quadro a este-bordo da barcaça que entra." Possivelmente, o artista tenha feito um dos últimos registros do lugar, já que em 1910 o forte foi demolido para a ampliação do porto. O pintor observa que, por ocasião da elaboração de sua obra, a construção "achase em completo abandono."

Pensemos no significado dessa anotação aposta à tela que permanecerá, ao longo dos anos, sendo admirada por seu proprietário-historiador. Quantas memórias ela contém sobre os acontecimentos marcantes da vida de Pernambuco. Mais que o valor artístico, impregnam a pintura a lembrança da ocupação holandesa, a questão do nascer de uma cidade litorânea, surgindo na área retratada, a portuária, portanto local onde se inicia a construção da própria identidade nacional, a primeira memória de um povo e, no caso do forte do Picão, há ainda o registro do patrimônio histórico pouco depois desaparecido.

Outra presença de um edifício histórico em deterioração é a tela Ruinas do convento do Carmo (ou das Carmelitas), em Olinda. O convento foi queimado em 1630 e suas ruínas testemunham a conturbada história local, transformando-se em mais uma imagem para a reflexão do historiador. Curiosamente, o pintor da luminosidade pernambucana elaborou na referida obra uma representação da noite. Trata-se da re-elaboração de um estudo realizado anteriormente, em 1889, à luz do dia. Se Telles Jr. posteriormente não fez outra tela noturna, temos na coleção Oliveira Lima uma verdadeira exceção, segundo a descrição no verso do quadro, "O presente quadro representa as ruínas iluminadas pelo luar depois de meia noite, impressão de minha volta do Recife depois da ópera; é o único estudo que fiz deste assunto representando a noite. Recife, 10 de Janeiro de 1907."

Encontramos integrando ainda a coleção de Oliveira Lima, três pequenas telas nas quais o verde impera. Duas delas formam o pendant "Derrubada de árvores". Em carta, de fevereiro de 1904, o escritor Artur Orlando ${ }^{21}$ informa ao amigo Oliveira Lima que: "O Telles está retocando os dois quadrinhos. Era o único pendant que ele tinha. Disse-me que de certo tempo para cá tem horror ao par na pintura."

As tratativas, para a obtenção de mais essa exceção da produção de Telles Jr. chegam a bom termo em maio daquele ano, quando Artur Orlando reforça em outra correspondência: "era o único pendant que existia. Ambos representam pontos do engenho do 
Ignácio de Barros na Várzea”. Identificamos, assim, através das cartas, o local retratado nos dois pequenos quadros. É interessante notarmos que nem sempre as telas que compõem o acervo Oliveira Lima estão nomeadas com os títulos a elas dadas por seus autores. A leitura das missivas recupera os nomes outorgados originalmente, além de nos esclarecer onde e, muitas vezes, em que circunstâncias as obras foram realizadas.

Em estudo publicado na Revista do Norte, Joaquim Cardozo considera Telles Jr. o pintor por excelência de paisagem litorânea pernambucana, observando ainda que a singularidade de sua produção estaria no tratamento da paisagem regional de forma inequívoca embora "romantizada por um sentimento misto de tristeza e de alegria". O poeta critica o quase total desconhecimento sobre essa criação tão genuinamente local, lamentando o difícil acesso à obra, desdenhada por governantes e autoridades que não prestigiam e divulgam o meritório trabalho." 22

Embora Telles Jr. seja o pintor pernambucano da época sobre o qual mais se escreveu, foi seguramente Oliveira Lima quem mais valorizou o seu trabalho, compondo-lhe os traços biográficos e o percurso artístico, tecendo considerações enaltecedoras sobre a sua verdadeira devoção pela natureza pernambucana e sobretudo reiterando a propriedade da representação de aspectos do litoral e do interior sertanejo onde viceja a luz dos espaços infinitos. ${ }^{23}$

A correspondência entre o crítico e o pintor traz os efusivos agradecimentos de Telles Jr. aos textos de Oliveira Lima, como podemos aquilatar pelo trecho final de uma carta de julho de 1905, referindo-se a matéria publicada na revista Kosmos:24 "Já tinha me esquecido que o meu amigo Dr. Alfredo de Carvalho tinha me pedido o retrato e a minha biografia, assim como me esqueço de quase tudo a não ser a minha tarefa quotidiana e o doce aconchego da família, e, neste sono, é que veio me encontrar o "Kosmos" com uma alvorada cheia de animação. Devo acordar ? Obrigado, meu bom amigo - muito obrigado ! Muito feliz me julgarei se conseguir fazer para mim uma realidade o que o Dr. Oliveira Lima firmou com o seu ilustrado e autorizado nome.

$$
\text { Amigo, Criado, Obrigado, Jeronimo J. Telles". }
$$

O fragmento de carta acima reforça um ponto relevante do perfil intelectual de Oliveira Lima, aquele do empenho de pesquisa. O historiador, além de pedir dados ao pintor através do amigo Alfredo de Carvalho, também pede informações ao amigo Baltar, outro colecionador de Telles Jr., como podemos constatar pela carta de Baltar a Lima encontrada no arquivo da Biblioteca Oliveira Lima. Nela, Baltar traça uma minuciosa lista das obras de Telles Jr. Parte das obras discriminadas estão fotografadas e no verso da maioria delas está anotado o local que representam, a data de sua feitura, bem como quem são seus proprietários. Tais dados, acreditamos, subsidiaram o estudo de Oliveira Lima sobre o artista.

Ainda na carta de maio de 1904 o pintor justifica-se em relação à encomendas ainda não concluídas: "Peço desculpas de já não ter lhe escrito a respeito de sua encomenda (...) Tem diversos quadros aqui aguardando a sua vinda, e como não tinha grande pressa do dinheiro, isto é: precisava de muito dinheiro, mas, do que o Dr. me deve poderei esperar até que nos encontremos - os quadrinhos são seus e outro não os levará". 
A carta em questão é assinalada pelo lamento do pintor. O tom melancólico, triste, já indicado por Joaquim Cardozo, é constante na vida de Telles Jr. Aliás, outros missivistas pintores, como Àlvaro Amorim, também aludem, como vimos, ao fato de encontraremse em lugar tão inacessível. Telles Jr. reclama estar "Isolado neste meio mesquinho e repugnante - sem ver nada - e no campo, na solidão que o meu espírito respira e dali volta cheio de oxigênio que em breve se esgota. Os produtos dessas horas cheias de vida são o lenitivo das minhas amarguras. Não tenho a pretensão de que meus quadrinhos valham alguma coisa, por isso, trabalho mais para mim e para os poucos bons amigos que os encarecem - e é por isso também que não sei dar o valor material aos meus trabalhos $(\ldots)^{\prime \prime}$

As desalentadas linhas comprovam a quase impossibilidade da projeção artística fora do Rio de Janeiro. A relação entre artistas e a academia é fundamental para a compreensão da mobilidade, da aceitação e da preferência no contexto de uma época na qual as distâncias geográficas representavam a quase anulação de uma produção local que existia de fato.

No decorrer de 1907 a correspondência entre historiador, que se encontra no Recife, e o pintor é significativa. As cartas registram as combinações acerca das visitas que Telles Jr. faz ao diplomata no engenho Cachoeirinha, propriedade do sogro de Oliveira Lima e no qual d. Flora passou a infância. Os excertos das cartas, a seguir, nos mostram o tom fraterno com o qual o pintor se dirigia ao diplomata, a constância da amizade, bem como as imensas dificuldades de locomoção naquela época:

"Estimado Amigo e Ilustre Sr. Dr. Oliveira Lima.

Recebi sua amável carta de 22 do corrente e por tudo quanto me diz gratidão para com V. Exa., por isso estou inteiramente satisfeito. Tendo meus filhos tomado trabalhos para o carnaval, vejo-me obrigado a estar naqueles dias a seu lado para guiá-los no que for preciso; por isso peço ao caro amigo que me permita antecipar minha ida a Cachoeirinha que será agora no ida 2 de fevereiro no trem da manhã.

Amigo grato Telles' 25

"Ilustre Amigo Sr. Dr. Oliveira Lima,

(...)

"Sinto bastante não me ser possível ir esta semana a Cachoeirinha, e se já não tenho me dirigido ao ilustre Amigo é porque ainda estava em dúvida se a resolução que deveria tomar, e mesmo porque julgava que, não sendo impossível a ida a esse local nestes dias, seria difícil devido a enchente do Pirapama que segundo noticias dos jornais tem alagado os caminhos nessa zona. Si o engenho fosse mais perto, eu me aventuraria a viagem, mas estou muito receoso do tempo (...)Quando me for possível ir, eu avisarei com a necessária antecedência.

Logo que aqui cheguei do meu agradável passeio a essa nobre casa onde fui tratado com tanta gentileza, e que tão gratamente me impressionou, comecei logo no outro dia muito cedo a reproduzir para a tela o esboço que d'aí trouxe e com bastante felicidade, pois o Dr. Artur quando (...) e entrou em nossa sala de trabalho (...) reconheceu a 
Cachoeirinha que se apresenta risonha em um belo dia de verão com os seus cercados queimados pelo sol, mas onde se sente a frescura de suas cascatas.(...)

Seu amigo e criado

Jeronimo Telles" 26

Segundo o jornalista Anibal Fernandes, a fatura teliana era tão peculiar que Oliveira Lima, visitando um dia a coleção de Belarmino Carneiro, deteve o olhar sobre duas paisagens, exclamando: "Isto é Pernambuco." - "Pois se são paisagens de Telles" - replicou Belarmino. Fernandes comenta a perspicácia da análise realizada por Oliveira Lima, ao dizer que o paisagista retratava de maneira única a cor local, revelando um sentimento nativista da luz, "da nossa luz, que esplende nos céus, estonteante, como um imenso diamante irisado, [e que] vem de alguns quadros". ${ }^{27}$ Nessa apreciação densa de sentimento, notando a relevância da expressão "da nossa luz", podemos atribuir às obras integrantes da coleção Oliveira Lima a especial significação que agrega simultaneamente o valor estético das obras, pois trata-se de um pintor de qualidades cada vez mais reconhecidas pela crítica, e o valor sentimental do convívio e da representação, segundo Oliveira Lima, tão fidedigna da luz que, vinda de alguns quadros tal qual "imenso diamante irisado", banhava, mundo afora, os lugares nos quais o diplomata viveu.

Em 1920 o Diário de Pernambuco publica matéria sobre a inauguração de um busto, realizado pelo escultor pernambucano Bibiano Silva, em homenagem a Telles Jr., falecido em 1914. Oliveira Lima é o presidente de honra da comissão preparadora da comemoração, e discursa por ocasião da solenidade, ressaltando ter sido o pintor aquele que "mais tem amado e melhor tem interpretado a natureza pernambucana." 28 Anos antes desta festividade, Oliveira Lima escreveu alguns textos sobre Telles Jr., no mesmo jornal. Eles sempre traziam alusão sobre a semelhança do pintor com um holandês "seu tipo físico havia muito de holandeses. Dir-se-ia antes um burguês da Mauricéia com sua barba loura." Em um dos artigos, no ano de morte do pintor, o historiador não se furtaria em manifestar seus próprios sentimentos ao evocar a vida e a obra do artista: "A riquíssima vida vegetal que o nosso solo comporta encontrou nele um entendedor e um apaixonado, porque é com carinho de amante que ele traduz nas suas telas, as quais de certo por isso tanto nos dizem à vista e à alma." ${ }^{29}$

Lembremos uma vez mais Gilberto Freyre. O antigo aluno de Telles Jr, em seu Guia de Olinda, vai no mesmo diapasão: "Que luz é esta ? (...) O nosso Teles sentiu bem essa luz; e com a luz, a paisagem pernambucana (...). ${ }^{30} \mathrm{O}$ sociólogo nos diz ainda que Recife é a cidade dos pintores, talvez por causa de sua luz.

Gilberto Ferrez, falando sobre a produção de paisagens em Pernambuco, considera a produção local de pouca quantidade, mas para ele Telles Jr seria "um dos melhores pintores paisagistas do país, no século passado." Teria sido "um dos primeiros a captar a luz crua e forte da região batendo em cheio nas gamas infindáveis do verde de nossas arvores, e, como bom brasileiro, um dos primeiros a recolher toda a beleza e poesia das paisagens dos arredores e praias do Recife. É o pintor por excelência das praias, dos coqueirais, dos cajueiros e dos arrabaldes modestos do Recife". ${ }^{31}$

Mais recentemente, além de Gilberto Ferrez, a grandiosa mostra dos 500 anos reiterou as palavras ditas décadas antes por Oliveira Lima. A exposição apresentou várias 
obras do artista, considerando Telles Jr. original no novo discurso sobre a paisagem regional. A distância dos centros formadores de arte teria na verdade favorecido a autonomia da fatura de Telles Jr. A vivência local favoreceria e conferiria afetividade à paisagem retratada, "não mais como a concebiam os viajantes, mas com a dimensão lírica do íntimo conhecimento das terras pernambucanas". 32

O último artista que abordaremos - este bem mais conhecido - é Antonio Parreiras (1860-1937). Considerado um dos maiores nomes das artes plásticas do entresséculos, o pintor carioca, nascido em Niterói, passou a infância nas praias de sua cidade natal, cenário recorrente de suas marinhas e paisagens. Inicialmente foi funcionário da Companhia Leopoldina em Nova Friburgo, não permanecendo por muito tempo nesse trabalho, pois o fascínio pela arte o levaria a dedicar-se à pintura, matriculando-se, tardiamente, na Academia Imperial de Belas-Artes. Entretanto, sua permanência na Instituição seria breve, pois desaprovando a rigidez do ensino, tornou-se discípulo do alemão Georg Grimm, que também deixara a Academia, quando nela ministrava aulas de Paisagem. Grimm havia se rebelado contra o método em uso de se ensinar paisagem em ateliê, e teria dito, com sotaque alemão, segundo Gonzaga Duque: "Quem quer aprender pintar, arruma cavalete, vai pra mato." O mestre abre, então, uma escola de pintura ao ar livre em Niterói, congregando alunos que dariam início ao paisagismo no Brasil, com o propósito de privilegiar a luz natural como contraponto à paisagem composta em recintos fechados. Parreiras, ao destacar-se do grupo, permaneceu nele pouco tempo, indo aprimorarse em Veneza. Quando de lá voltou, organizou uma exposição com a produção realizada, sendo então convidado a lecionar Paisagem na Academia Imperial de Belas Artes, na qual, mais uma vez, sua estada foi efêmera, pois o artista preferiu estabelecer sua própria escola em Niterói, significativamente intitulada Escola ao Ar Livre, a exemplo da Escola da Boa Viagem, anteriormente liderada por Grimm.

Por toda a vida Parreiras ganhou muitos prêmios, participou de inúmeras mostras e certames. Sua carreira cumulou-se de encomendas, viagens, longas permanências em Paris, onde mantinha ateliê, participava dos salões oficiais e tinha reconhecimento da crítica francesa. Em 1925, foi eleito o mais famoso pintor brasileiro em concurso promovido pela revista Fon-Fon e, no ano seguinte, publicou sua autobiografia - História de um pintor contada por ele mesmo. $\mathrm{O}$ artista teria produzido, segundo seus próprios cálculos, cerca de 850 telas. Em tudo uma trajetória diferente daqueles percursos descritos até aqui.

Depois de se dedicar vinte e dois anos às paisagens, em fase posterior, realizou muitos nus, e, com o advento da República, parte substancial de sua produção constituiu-se de inúmeras encomendas de cenas com temas históricos. O recém criado governo republicano precisava aparelhar simbolicamente seus palácios em diversos estados brasileiros. As excursões à mata para apreender melhor a natureza, as longas sessões dos modelos nus, dão lugar, então, ao que chamaríamos de "peregrinações" através do Brasil, para que seus serviços de pintor e decorador fossem contratados.

O estudo das cartas enviadas pelo artista a Oliveira Lima nos permite compreender a dinâmica das relações, na qual o pintor alia exposições por todo o Brasil com a venda das obras expostas e contatos em jornais, cartas para amizades influentes e acesso aos governantes com o intuito de conseguir novos trabalhos. As "peregrinações" eram fun- 
damentais, pois sua presença física era marcante e legitimava sua obra. Em suas incursões pelo Brasil afora, Parreiras se fazia magnânimo, principalmente longe do epicentro das artes, que era o Rio de Janeiro. Sua visita ao Recife exemplifica a múltipla ação do artista para atender a todas as atividades que fariam sua viagem auferir lucros de prestígio e, sobretudo, financeiros. Na capital pernambucana, por exemplo, em maio de 1917, ele expõe quarenta e duas obras, mais dois croquis, conforme podemos ler no catálogo da mostra. Ministra aulas gratuitas, numa espécie de "workshop", comparece às sessões do organismo de fomento à arte local, o Círculo de Belas Artes de Recife, do qual, aliás, torna-se sócio-correspondente, além de comparecer a banquetes em sua homenagem. Faz doação de obras, como é o caso de Flor brasileira, de 1912, para criação da Pinacoteca do Recife, ${ }^{33}$ assim como presenteia Flora de Oliveira Lima com um esboço, realizado durante a sua visita ao Recife, retratando o forte do Buraco. ${ }^{34}$

Todas as suas atividades são registradas pelos jornais locais com grande destaque, como vemos nos recortes dispostos no scrapbook referente ao período, selecionados por d. Flora. É evidente que a visita de um renomado artista ganha espaço e repercussão nos jornais. Visitar o próprio veículo de imprensa acompanhado de figura insigne da cidade era uma atitude prevista, como podemos ver na coluna "Artes de Artistas" de O Diário de Pernambuco: "Acompanhado do nosso eminente colaborador dr. Oliveira Lima, visitounos ontem o consagrado pintor Parreiras." 35 Mas a profusão dos compromissos e seus esforços na articulação das variadas inserções sociais que poderiam tornar mais evidente sua estada na capital de Pernambuco, denotam o esforço do artista em estar em todos os lugares para promover sua obra.

Não é o que depreendemos quando lemos a entrevista dada pelo pintor a Angyone Costa. Ele diria: "Talvez por sorte, vendi sempre os meus trabalhos com relativa facilidade" ${ }^{36}$ Não é isso que nos parece, ao vermos os artigos referidos acima, nem tampouco o que relatam as cartas enviadas por Parreiras a Oliveira Lima, e foram mais de quarenta delas. As missivas trazem, invariavelmente, um tom desalentado, enfatizando a impossibilidade em vender suas obras, e o abandono ao qual as autoridades republicanas relegavam os artistas brasileiros. Vejamos uma carta enviada pelo artista ao diplomata, em 1912:

"Meu caro amigo:

(...)Deixei Paris crente de voltar 4 ou 5 meses mais tarde,(...) alimentava a esperança de, em chegando ao Brasil e com a venda dos meus trabalhos, eu arranjaria algum dinheiro e poderia voltar (...) a minha exposição produziu geral agrado, mas só vendi um quadro por 300 mil reis !!! Procurei por todos os meios ver se vendia a Dolorida ao governo e até hoje nada obtive, embora ainda este ano um artista italiano e outro espanhol tenham vendido quadros ao Brasil pela importância de 54 contos de reis. Quadros que lá estão na Escola de Belas Artes. Infeliz na exposição(...), parti para o Rio Grande do Sul levando uma enorme bagagem. Em Porto Alegre fiz uma exposição onde vendi apenas dois quadros cuja importância não deu para as despesas. Felizmente o Dr. Borges de Medeiros veio em meu auxílio e fez com que o governo me encomendasse um quadro no valor de 28.000 (trata-se da tela Proclamação da República riograndense). 
Não posso porém dedicar-me a este trabalho, pois que não tenho recursos para o fazer, faltam-me modelos e sobretudo a calma, (...) junta-se a estupidez deste viver neste meio acanhado, atrofiante onde me debato e de onde não sei quando poderei sair.

Agora vou tentar uma nova cartada - vou fazer uma grande exposição em São Paulo onde sempre fui feliz.(...)

Do meio deste terrível ambiente eu faço sinceros votos para que seja feliz em companhia da Exma. Senhora a quem tenho esperança, hei de ter o prazer de entregar pessoalmente um quadrinho do Brasil que lhe prometi.

(...)e receba um forte abraço do saudoso amigo

Parreiras." 37

Mesmo quando Oliveira Lima e Parreiras estiveram em Recife, entre os meses de maio e julho de 1917, há troca de correspondência nos esclarecendo ainda mais sobre o empenho de Parreiras em conseguir encomendas, e, de volta ao Rio de Janeiro, uma carta resume os esforços da temporada no Nordeste:

"Meu caro amigo:

Eis me de novo no Rio (...)Cheguei na Bahia em um Domingo (...) Ao passar por Vitória procurei o Dr. Paes Barreto - ele não estava na cidade, tinha ido com a família para a roça. Não faz mal, ficará para a minha volta e farei o pedido da encomenda apresentando o croquis.

(...) Sabe por que o Borba não encomendou o quadro ? Porque o Medeiros de Albuquerque assim lhe pediu para se vingar de mim, por ter lhe qualificado de venal em um telegrama que dirigi ao Dr. Lauro Müller. Soube disto no congresso, logo que aqui cheguei, pois a um deputado o venal do Medeiros lhe disse que a seu pedido o Borba nada me encomendaria.

(...)E sem mais, aceite muitas e muitas recomendações (...) do amigo muito agradecido,

Parreiras." 38

Parreiras empenhou-se consideravelmente em pesquisas para a realização das encomendas feitas a ele, sobretudo as relativas à pintura histórica. Talvez este seja o principal motivo que o leva a corresponder-se assiduamente com Oliveira Lima, o historiador mais reconhecido em sua época. Este, sempre solícito, alternava instruções em cartas e referências elogiosas nos artigos compostos para os vários periódicos para os quais colaborava, como é o caso da matéria "Coisas Nacionais", onde aprecia os trabalhos que o pintor preparava para a representação do Brasil na Exposição de Turim. Oliveira Lima é enfático ao comentar a brasilidade advinda das composições: “Quando ultimamente estive em Paris (...) visitei o ateliê de Parreiras, e lá tive o prazer de admirar, (...) os painéis decorativos (...) vi como um artista brasileiro foi imediatamente, talvez mesmo instintivamente, procurar seus motivos na transformação que está na base do nosso desenvolvimento, que forma nossa evolução, que constitui a trama da nossa história social." ${ }^{39}$

Parece-nos que o historiador é grande admirador do pintor, tanto da paisagem quanto das pinturas históricas, e mesmo dos nus, já que adquiriu a tela Frinéia, um nu assinado 
por Parreiras e premiado em Paris. Oliveira Lima apreciava igualmente a preocupação com a identidade brasileira que teria sido uma constante na obra do artista fluminense. Maciel Levy afirma, como estudioso da obra do pintor que "Parreiras é indiscutivelmente o mais importante dos paisagistas brasileiros (...) consolidou a mais enérgica vocação de paisagismo naturalista, romântica e ousada, até então ocorrida no Brasil (...) obteve motivação através de artifícios psicológicos os mais variados, tais como uma profunda noção de brasilidade e de sua ingênua crença nos valores de uma hipotética nacionalidade cultural". ${ }^{40}$

Oliveira Lima sempre se interessou pelas artes plásticas. Escreveu textos de crítica de arte ao longo de sua existência, muitos publicados em revistas cariocas, outros, sem assinar, para a coluna 'Notas de Arte" do Jornal do Recife. Além de rticipou do Círculo de Artes de Recife, presidiu comissões julgadores de prêmios, em sua biblioteca há obras importantes sobre o assunto. Comprou e ganhou obras que decoravam sua residência e posteriormente passaram a integrar a Biblioteca Oliveira Lima, em convívio estreito com seus livros.

Nas poucas telas que comentamos aqui, pequena parte, como dissemos, de um conjunto de vários gêneros, o que observamos é sempre a presença ora da mata, ora do mar, a largueza do espaço, marcos da definição de um Brasil luso-brasileiro, como é o caso das fortificações. Como se Oliveira Lima trouxesse o mundo natural e inculto para o mundo civilizado das capitais em que morou. Não nos esqueçamos de que o vocábulo paisagem deriva de país, e a natureza interpretada como pátria está na base da reflexão sobre identidade e nacionalidade, preocupações constantes do historiador-colecionador Oliveira Lima.

\section{Notas}

1 Referência à obra de Cicero Dias (1908-2003).

2 Este estudo integra uma pesquisa mais ampla sobre as pinturas e seus autores, que compõem o acervo de artes plásticas da referida biblioteca.

3 In Rubro Veio, o imaginário da restauração pernambucana. $2^{\text {a }}$ edição, revista e aumentada, Rio de Janeiro: Topbooks, 1997 , p. 59.

4 Eustórgio Wanderley, "Arte Brasileira”, in Revista do Instituto Arqueológico Histórico e Geográfico de Pernambuco, vol XXXII, números 151 a 154, 1932. p. 309-313. O autor deste texto pertencia ao Círculo das Artes, instituição da qual Oliveira Lima também participava.

5 Oramas, Luís Peres. "Paisagem e fundação: Frans Post e a invenção da paisagem americana" in XXIV Bienal de São Paulo: Núcleo Histórico: Antropofagia e Histórias de Canibalismos, vol. 1, São Paulo: A Fundação, 1998. p. 102-106

6 Atualmente a tela "Brazilian Landescape, Said to be Pernambuco", encontra-se na Nacional Galery de Washington.

7 Ver Pedro Correia do Lago, "Frans Post e seu tempo" in O olhar distante, Mostra do redescobrimento, 2000. p. 74-109.

8 Oramas, op. cit. p. 102.

9 José Roberto Teixeira Leite. Viajantes do Imaginário: A América vista da Europa, séc. XV-XVII. In Dossiê Brasil dos viajantes, Revista USP, número 1, mar./mai.1989.

10 Ver sobre o assunto o texto de Blanche Ebeling Koning. "The rare book collection at the Oliveira Lima Library, an overview," neste volume.

11 Cf. “Um senhor feudal supersticioso e pornográfico”, , entrevista a Mário Sérgio Conti em 14.02.2002. http:/ /www.nordesteweb.com. 
12 Lucilo Varejão, "50 anos de pintura em Pernambuco" in Revista Arquivos ano 1 no 2 novembro de 1942, Prefeitura Municipal de Recife, p. 171-178., p. 174

13 cf. Otávio Brandão, "O forte do Buraco" in Revista do Instituto Arqueológico e Geográfico de Pernambuco. Vol. XVI 1911 à 1914 números 83 a 86. Recife: Imprensa Industrial, 1914, p. 158

14 Carta de 24 de abril de 1922.

15 Chambelland (1884-1950), De sua permanência em Pernambuco disse o pintor: "O Rio e o sul do país estão muito trabalhados pela influência estrangeira, e o cosmopolitismo absorveu-nos tanto, que hoje, somente no Norte, se nos depara, em sua pureza inicial, o sentimento da pátria aferrado à tradição, aos costumes, à vibração da alma do povo. Acredite, pela primeira vez envaideci-me da minha nacionalidade, quando vivi três anos - os melhores da minha vida - em Pernambuco." cf. in José R.T. Leite, Dicionário crítico de pintura, op. cit., p.118.

16 Ver o texto "Os irmãos Bernardelli” in Angyone Costa, A inquietação das abelhas, Rio de Janeiro: Pimenta de Melo \& Cia. 1927.p. 27 e seguintes. Ver ainda, "O ensino de desenho e pintura” in José Carlos Durant, Arte, Privilégio e Distinção. São Paulo: Editora Perspectiva/Edusp, 1989, p. 47 e seguintes.

17 Gilberto Freyre. "Telles Júnior, mestre de desenho e pintor da mata pernambucana" in Pessoas, coisas e animais, $1^{\mathrm{a}}$ série. Porto Alegre/Rio de Janeiro: Segunda edição. Editora Globo, 1981. p. 101 e seguintes.

18 Gilberto Freyre se remete a: Telles Jr. "Memórias" in Revista do Arquivo Público do Estado de Pernambuco, dezembro de 1974, v.XI/28.

19 "Memórias", op. cit.

20 Gilberto Freyre, op. cit. p.106.

21 Artur Orlando (1858-1916), advogado, jornalista, ensaista, deputado, senador. Foi missivista de Oliveira Lima no período de 1891-1914, parte das cartas versam sobre a produção de Telles Jr.

22 Joaquim Cardozo, "Sobre a pintura de Telles Jr." in Revista do Norte, $2^{\text {a }}$ fase, número 2, agosto de 1926.

23 Oliveira Lima. "Um paisagista pernambucano: Telles Jr." in Revista do Instituto Arqueológico e Geográfico Pernambuco n. 86, Recife, 1914, p.120-124; “Coleção Telles Jr., Recife. 1942, Pinacoteca do estado de Pernambuco. 24 O artigo publicado por Oliveira Lima na revista Kosmos de maio de 1905 (ano 2, n.5) tem o mesmo título, "Um paisagista pernambucano: Telles Jr." do texto publicado na Revista do Instituto Histórico e Geográfico Pernambucano de 1914.

25 Carta de 28 de janeiro de 1907.

26 Carta de 27 de março de 1907.

27 Anibal Fernandes, “Três pintores do Nordeste”, in Estudos Pernambucanos. Recife. p. 106.

28 Diário de Pernambuco, 14.06.1920.

29 “Telles Jr., a comemoração de hoje”, Diário de Pernambuco, 14.10.1914.

30 Gilberto Freyre, Guia prático, histórico e sentimental da cidade do Recife, $4^{\mathrm{a}}$ edição, revista, atualizada e muito aumentada. Rio de janeiro: José Olympio:1968. p. 13.1.

31 Gilberto Ferrez em Exposição Comemorativa do Tricentenário da restauração pernambucana. Iconografia do Recife séc. XIX. Comissão Organizadora e Executiva. Pe. 1954.p. 5, 6.

32 Catálogo da Exposição Mostra do redescobrimento, Arte no século XIX, Fundação Bienal de São Paulo, 2000, p. 180.

33 A Pinacoteca do estado de Pernambuco foi criado 1928.

34 Conforme notícia de jornal aposto no scrapbook do ano de 1917.

35 Diário de Pernambuco, 24.05.1917.

36 Angyone Costa, op. cit., p. 71

37 Carta de 02 de maio de 1912.

38 Carta de 29 de julho de 1917.

39 “Coisas Nossas" in O Estado de S. Paulo, 09 de fevereiro de 1911.

40 Maciel Levy, Antonio Parreiras: pintor de paisagem, gênero e história. Rio de Janeiro: Galeria de Arte, 1981, p. 57. 